Research Article

\title{
Knowledge, attitude and practice study regarding pharmacovigilance programme of India among private practitioners in urban Odisha, India
}

\author{
Trupti Rekha Swain*, Neha Nityadarshini, Suchismita Pattnaik, \\ Kali Prasanna Swain
}

Department of Pharmacology, In Charge Clinical Pharmacology

Unit, SCB Medical College,

Cuttack, Odisha, India

Received: 01 April 2016

Accepted: 04 July 2016

*Correspondence to:

Dr. Trupti Rekha Swain,

Email: drtruptiswain@

gmail.com

Copyright: (C) the author(s), publisher and licensee Medip Academy. This is an openaccess article distributed under the terms of the Creative Commons Attribution NonCommercial License, which permits unrestricted noncommercial use, distribution, and reproduction in any medium, provided the original work is properly cited.

\begin{abstract}
Background: Private health care providers play an important role in health programmes of a country. Pharmacovigilance programme of India (PVPI) seeks involvement of different health sectors to make it successful. Knowledge, attitude and practice (KAP) studies provide a base line information about human behaviour and practices so that a properly planned acceptable intervention can be made.

Methods: level of knowledge, attitude and practice regarding pharmacovigilance programme of India was evaluated among doctors working in private hospitals/clinics of Bhubaneswar and Cuttack city of Odisha. A thirty three item questionnaire was used to collect the data which contained 12 knowledge, 12 attitude and 9 practice based questions.

Results: Only fifty four out of 124 participating doctors responded positively. The knowledge level of practitioners was found to be acceptable with $38.9 \%$ subjects scoring more than $70 \%$. However a gap in knowledge was observed regarding some specific area and was not translated in terms of good quality reporting of ADRs. Only $13(24.1 \%)$ practitioners were found to have actually reported ADR to Pharmacovigilance centre.

Conclusions: Adequate awareness should be created among private practioners regarding the pharmacovigilance programme of India. Easy accessibility of ADR forms and appropriate educational intervention through media can improve ADR reporting.
\end{abstract}

Keywords: PVPI, ADRs, KAP, Pharmacovigilance

\section{INTRODUCTION}

Rise in the introduction of newer drugs in the market has increased the need to monitor the adverse drug reactions (ADRs) in order to ensure patient safety. To overcome this need, a nation-wide Pharmacovigilance Programme was initiated by the Govt. of India (PVPI) with an objective to assure drug safety. Even after a decade of its initiation, the programme is in the stage of infancy. This is evident from the fact that there is a high level of underreporting of ADRs. ${ }^{1}$ A total of $3.7 \%$ of hospitalized patients experience an ADR, of which $1.3 \%$ was fatal. ${ }^{2}$ ADRs increase the financial burden on the patients and hospital apart from contributing to the mortality and morbidity of patients. ${ }^{3}$ This reflects a huge need to create awareness among the medical practitioners regarding Pharmacovigilance. According to national family heath survey-3, the private medical sector remains the primary source of health care for the majority of households, especially in the urban areas $(70 \%){ }^{4}$ In Odisha, about $64 \%$ of private hospitals and $71 \%$ of total private beds are in the urban areas. ${ }^{5}$ Pharmacovigilance programme of India (PVPI) can never be successful without active involvement of healthcare professionals like doctors, dentists, nurses, and pharmacists in the private sector. If sensitized properly, the doctors in private sectors can play a significant role in the reporting of ADRs as the Peripheral Pharmacovigilance centres are usually located in tertiary care centres, in urban areas. The study aims at assessing awareness regarding the programme and 
evaluating knowledge, attitude and practices among the doctors working in the private sector hospitals of urban Odisha.

\section{METHODS}

This cross-sectional open level observational questionnaire based study was conducted among the private practitioners of Cuttack and Bhubaneswar municipal areas. The present study was conducted after obtaining necessary permission from institutional administration and ethical committee of SCB Medical College, Cuttack. This survey was conducted for a period of four months from May to August 2013. Complete enumeration of all available doctors who could participate in the study was done depending on time availability and feasibility factor. In total 124 doctors from both Cuttack and Bhubaneswar was targeted for this survey. A pre-tested semi-structured questionnaire (appendix-1) was designed and developed to collect information with respect to knowledge, attitude and practices of the private medical practitioners regarding their ADR reporting practice and the pharmacovigilance programme of India. A study questionnaire consisting of 33-item, regarding demographic baseline data, ADR reporting knowledge, attitude assessment, and practices was used for collecting data. The questionnaire contained 12 knowledge assessment questions scored ( 0 for wrong and 1 for correct response) for each item, 12 attitude questions scored from 1 to 5 (Likert scale) for each item, and 9 practice questions scored based on correctness of response. Each of the participants was contacted personally. The purpose of the study and instructions for filling were explained and informed consent was obtained. The doctors were requested to complete the questionnaire and hand it back immediately, and those who were busy at that moment were requested to return back the duly filled questionnaires within 3 days. Sincere attempts were made to retrieve the properly filled questionnaire by mobile phone reminders. Participants, who failed to return the questionnaire, were not willing to participate at the time of giving or retrieving the questionnaire or who were unable to be contacted even after 3 reminders were excluded for data analysis.

The knowledge level of each person was determined by (score obtained/maximum score) X 100. Similar technique of scoring and determining level of attitude and practice was also done. Subjects were later stratified into various knowledge levels (less than 50\%, 50-70\% and $70 \%$ above) based on the above scoring methodology.

\section{Statistical analysis}

Data was entered in MS Excel and analysed accordingly. Prior to analysis, data was cross checked and validated for outliers, wrong entry and missing items. Qualitative data like gender, educational status, and training with respect to $\mathrm{ADR}$ reporting, was expressed in frequency and percentages. The proportion of correct and incorrect responses to knowledge, attitude and practice methods was expressed in frequency and percentages. The mean knowledge, attitude and practice score was expressed in mean \pm SD. The stratified groups namely $<50 \%$ score, 50 $70 \%$ and $70 \%$ above were expressed as frequency and percentages.

\section{RESULTS}

Out of 124 participating doctors who agreed to participate in the study, 54 questionnaires were duly filled and returned, thus giving a response rate of $43.5 \%$. Out of the total 54 subjects, $32(59.3 \%)$ were males and $22(40.7 \%)$ were female doctors. 51 (94.4\%) doctors had MBBS degree while $3(5.6 \%)$ were dental graduates.

The proportional distribution of correct and incorrect responses to knowledge assessment about Pharmacovigilance and ADR reporting is presented in Table 1. Mean knowledge score was 8.18 2 2.82. Different factors that are considered for deciding a symptom as ADR is depicted in Figure 1.

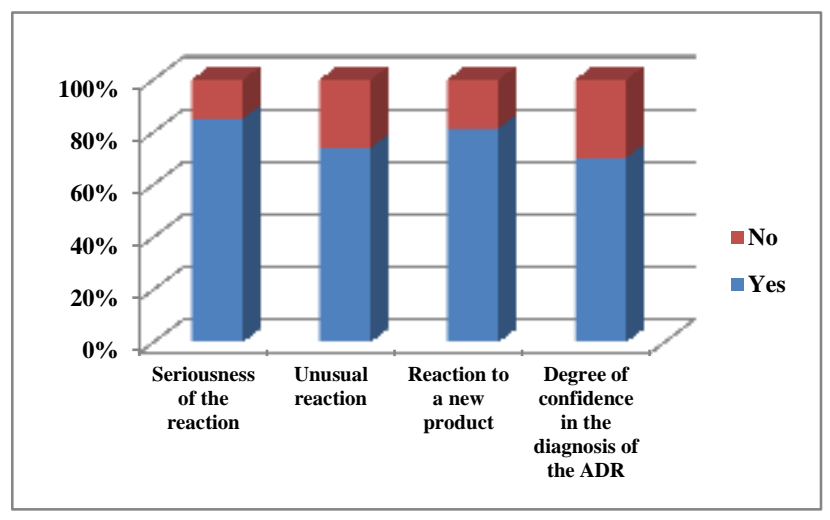

Figure 1: Factors for deciding symptoms as ADR.

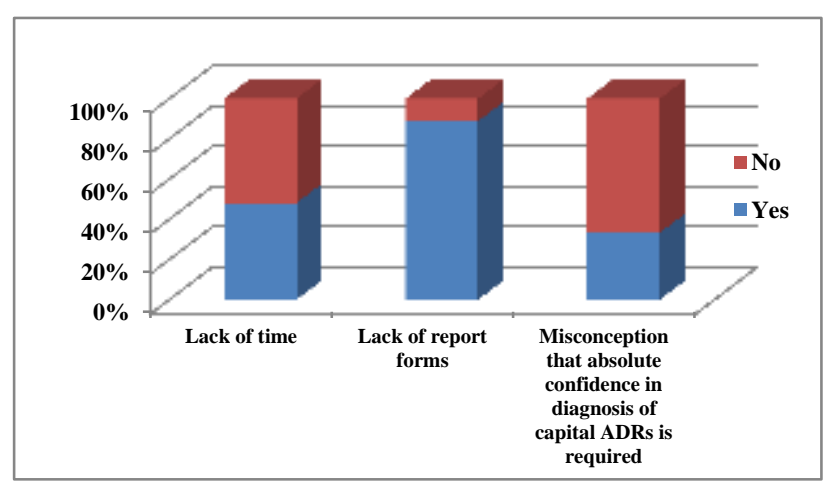

Figure 2: Reasons for not reporting ADRs.

Categories in which more than $75 \%$ correct response were obtained. Knowledge regarding drugs is the most important factor necessary to report an adverse drug reaction followed by serious ADRs are well documented by the time a drug is marketed and the national pharmacovigilance centre of India is located at New Delhi. 
Table 1: Evaluation of knowledge of private practitioners.

\begin{tabular}{|lll|}
\hline Item & Correct (\%) & Incorrect (\%) \\
\hline Pharmacovigilance activity was started in the year 2003. & $2(3.7)$ & $52(96.3)$ \\
\hline $\begin{array}{l}\text { The peripheral Pharmacovigilance Centre in Odisha is located at Pharmacology Dept } \\
\text { of SCB Med College, Ctc }\end{array}$ & $24(44.4)$ & $30(55.6)$ \\
\hline Naranjo algorithm scale is used to establish the causality of an adverse drug reaction. & $11(20.4)$ & $43(79.6)$ \\
\hline $\begin{array}{l}\text { Knowledge regarding drugs is the most important factor necessary to report an } \\
\text { adverse drug reaction. }\end{array}$ & $42(77.8)$ & $12(22.2)$ \\
\hline $\begin{array}{l}\text { Upon the occurrence of an ADR, what needs to be done with the suspected drug } \\
\text { depends upon the drug and adverse drug reaction. }\end{array}$ & $22(40.7)$ & $32(59.3)$ \\
\hline $\begin{array}{l}\text { Commonly encountered adverse drug reactions are allergic reactions, symptoms of } \\
\text { upper gastrointestinal irritation pyramidal symptoms and hepatitis. }\end{array}$ & $38(70.4)$ & $16(29.6)$ \\
\hline Serious ADRs are well documented by the time a drug is marketed & $43(79.6)$ & $11(20.4)$ \\
\hline The important factors for deciding a symptom as ADR & Yes & No \\
\hline $\begin{array}{l}\text { (a) Seriousness of the reaction } \\
\text { (b) Unusual reaction } \\
\text { (c) Reaction to a new product } \\
\text { (d) Degree of confidence in the diagnosis of the ADR }\end{array}$ & $46(85.2)$ & $8(14.8)$ \\
\hline $\begin{array}{l}\text { Med Watch is the WHO online data base for reporting adverse drug reaction by the } \\
\text { member countries }\end{array}$ & $44(81.1)$ & $14(25.9)$ \\
\hline $\begin{array}{l}\text { The common offending groups of drugs causing these ADRs are non-steroidal anti- } \\
\text { inflammatory drugs, anti-dopaminergics and chemotherapeutic agents. }\end{array}$ & $28(38.7)$ & $10(18.5)$ \\
\hline The National Pharmacovigilance Centre of India is located at New Delhi & $41(88.9)$ & $6(11.1)$ \\
\hline The international centre for adverse drug reaction monitoring is located in Sweden & $8(14.9)$ & $13(24.1)$ \\
\hline
\end{tabular}

Table 2: Knowledge and attitude score among private practitioners.

\begin{tabular}{|lll|}
\hline Score groups (\%) & Knowledge $(\%)$ & Attitude $(\%)$ \\
\hline$<50 \%$ score & $13(24.07)$ & $1(1.85)$ \\
\hline $50 \%$ to $70 \%$ & $20(37.04)$ & $3(5.55)$ \\
\hline$>70 \%$ & $21(38.89)$ & $50(92.59)$ \\
\hline
\end{tabular}

Less than $10 \%$ correct response was obtained regarding pharmacovigilance activity was started in the year 2003 and fact that med watch is the WHO online data base for reporting adverse drug reaction by the member countries. Mean attitude score was 86 percentages. 52 subjects $(96.3 \%)$ strongly agreed that it is necessary to report ADRs while $36(66.7 \%)$ strongly agreed that prescribers need periodic reinforcement regarding ADR monitoring. Table 2 shows the knowledge and attitude score among private practitioners. Thirteen $(24.1 \%)$ practitioners were found to have reported ADR to pharmacovigilance cell, $25(46.3 \%)$ doctors stated to have come across one ADR / month, 19 (35.2\%) came across ADR about <1/week, 26 (48.1\%) prefer reporting ADR to higher authority while $25(46.3 \%)$ report ADR to pharmacovigilance centre, Among those who have reported, 87\% doctors used prescribed format given by pharmacovigilance centre. Thirty-three doctors $(61.1 \%)$ depended on past knowledge and experience to confirm ADR whereas 21(38.9\%) prefer to follow relevant literature. Forty-two doctors (77.8\%) stated to have faced difficulty in reporting ADR, the major reasons being lack of knowledge on how and whom to report and not having access to report form (Figure 2).

\section{DISCUSSION}

Pharmacovigilance is the science relating to the collection, detection, assessment, monitoring, and prevention of adverse effects with pharmaceutical products. ${ }^{6}$ The reactions are defined as any response to a drug that is noxious and unintended, including lack of efficacy, which occurs at doses normally used for the prophylaxis, diagnosis or therapy of disease, or for the modification of physiological function. Information received from patients and healthcare providers, as well as other sources such as the medical literature, plays a critical role in providing the data necessary for Pharmacovigilance to take place. In fact, in order to market or to test a pharmaceutical product in most countries, adverse event data received by the license holder (usually a pharmaceutical company) must be submitted to the local drug regulatory authority. Ultimately, pharmacovigilance is concerned with identifying the hazards associated with pharmaceutical products and with minimizing the risk of any harm that may come to patients.

Most of the previous studies conducted in India indicate a lack of awareness about PVPI and ADR reporting. According to a study in a tertiary care teaching hospital in Nagpur, only $52.38 \%$ were aware about an ADR reporting 
system in India. ${ }^{7}$ As per another study carried out at MTH, a 700 bedded tertiary care hospital located in Western region of Nepal, the overall KAP scores among doctors were low. ${ }^{8}$ There was under-reporting and lack of knowledge. The findings suggested the need for proper sensitization and strategic interventions. However, there are inadequate studies in the private sector regarding other parameters like easy availability of ADR forms, incentives to doctors for reporting, improving awareness etc. Hence, further studies on this topic, especially in the private sector can bring out a better picture of the present scenario. Lopez Gonzalez E et al have suggested that, under reporting is a general phenomenon. ${ }^{9}$ It is found that only $6-10 \%$ of all ADRs are reported. ${ }^{10,11}$ This high rate of underreporting is a matter of great concern which can delay detection of serious ADRs and consequently have a major negative impact on the public health. Various factors have been attributed for underreporting of ADRs among health professionals. These factors are based on knowledge and perception of health professionals to reporting. Inman G. has described them as "seven deadly sins." That generally prevents the physicians to report an ADR. These include: financial incentives: rewards for reporting; legal aspects: fear of litigation or enquiry into prescribing costs and ambition to compile or publish a personal case series; complacency: the belief that very serious ADRs are well documented by the time a drug is marketed; diffidence: the belief that reporting an ADR would only be done if there was certainty that it was related to the use of a particular drug; indifference: the belief that the single case an individual doctor might observe could not contribute to medical knowledge; ignorance: the belief that it is only necessary to report serious or unexpected ADRs, and excuses made by professionals; and lethargy: the procrastination and disinterestedness in reporting or lack of time to find a report card, and other excuses. ${ }^{12}$ The factors responsible for underreporting have not been extensively studied in India. A previous study from India has found inadequate knowledge of resident doctors about ADRs. ${ }^{13}$

A study, conducted in zonal manner including 1200 randomly selected subjects, 300 from each zone, revealed that practitioners are aware of ADR reporting. ${ }^{14}$ Their perception towards ADR reporting is right. However it is not reflected when it comes to the act of reporting of ADRs. In the sample of 870 respondents only $18.5 \%$ had reported $\mathrm{ADRs}$ to some organizations. Only 5\% of respondents recorded the details of $\mathrm{ADR}$ and reported to the manufacturer and $1 \%$ of respondents to government health ministry. Medical practitioners in India appeared to have a good knowledge about ADR reporting and the right perception towards ADR reporting. However, as far as practice of ADR reporting is concerned it was discouraging.

There are even less number of studies conducted in the private sector. A study conducted in Klang Valley in Malaysia regarding knowledge, practices and attitudes towards adverse drug reaction reporting by private practitioners revealed unsatisfactory level of knowledge, practices, and attitudes towards ADR reporting among high proportion of private practitioners in Klang valley, Malaysia. $^{15}$

Almost all studies conducted in India and abroad regarding the current topic have been questionnaire based studies. A study conducted in UK regarding the attitudinal survey of adverse drug reaction reporting by medical practitioners used a postal questionnaire based on a previous one but with some modification. ${ }^{16}$ Similar method has been used in studies done in some tertiary care hospitals and teaching hospitals in India. The present study evaluates the perception of private doctors towards PVPI as well as assesses the factors responsible for underreporting. The present study was conducted among the private practitioners in Cuttack and Bhubaneswar regarding the pharmacovigilance programme of India. Though a decade has passed since the initiation of this programme, only $2(3.7 \%)$ subjects were aware of the year of its initiation. Similar response regarding knowledge about WHO online base, International monitoring centre indicates that there is a knowledge gap among the private practitioners. This shows a need for creating awareness regarding pharmacovigilance programme of India. However, unlike other previous studies, the knowledge level of study subjects regarding the location of peripheral Pharmacovigilance centre and commonly occurring ADRs is acceptable. ${ }^{18}$ An overall acceptable knowledge level may be attributed to the fact that the current study was conducted in an urban area where exposure to knowledge sources like print media, journals, workshops etc. is a common phenomenon.

Though most of the doctors were aware about reporting, there was lack of knowledge and motivation on how to report. Lack of proper format for submitting ADR s was found out to be an important indicator of no reporting. Misconception that, absolute confidence in diagnosis of ADR is essential before reporting was an important contributor in their decision to report ADRs. Unlike other studies lack of time was not found out to be an important reason for under reporting. ${ }^{9}$ Lack of knowledge regarding how and who to report was one of the reasons for not reporting an ADR by the private doctors in general.

This study revealed that attitude of the private medical practitioners was acceptable and their attitude towards the good clinical practice was very much appreciable. This finding is reflected by the fact that, almost all subjects believed that it is necessary to report ADRs. This result is similar to most of the previous studies conducted in India. ${ }^{18}$ Interestingly; about $75 \%$ practitioners agree that physicians are obliged to report ADRs although only 13 (24.1\%) doctors were found to have ever reported an ADR. This implies that the procedure of reporting should be made more accessible and feasible and awareness should be created about how to report. 
As far as practice is concerned, it was found out to be quite optimistic though some gap was observed. Majority of the study subjects $(48.1 \%)$ reported ADR to higher authority instead of the Pharmacovigilance centre, although $87 \%$ of the subjects knew that there is a specific format for reporting ADRs. This implies that awareness should be created particularly about whom to report. Both Print and TV media should be used for the same. An important point to rise regarding practice is underreporting of ADR. This is clearly evident from the fact that only $24 \%$ practitioners have ever reported an ADR. Almost $89 \%$ doctors cited the reason to be lack of report forms. Hence, effort should be made to make the availability of report forms easier in the private sector. This may greatly improve the rate of reporting of ADRs. Apart from this, like most of the other studies, lack of report forms and the misconception that absolute confidence in the diagnosis of an ADR is essential before reporting was major factors for not reporting ADRs among private doctors. ${ }^{3}$ Apart from creating awareness, educational intervention can significantly help sensitize the doctors regarding importance of Pharmacovigilance. Although a number of studies have been conducted about Pharmacovigilance and ADR reporting, a considerable part remains unexplored. An interesting question arising here is whether providing incentives to doctors can improve ADR reporting. Further research on this topic can reveal what kind of incentives doctors would prefer like monetary or name published in journals or concealed identity to avoid legal implications etc. Another aspect to consider here is how to make ADR reporting more simpler and less time consuming possible solutions may be ADR drop-boxes. ${ }^{19}$ Further studies can throw more light in this direction. More studies with larger samples targeting the private sector can bring out a better picture regarding the status of pharmacovigilance among private practitioners in other parts of the region. A full cooperation from private sector would ensure success of pharmacovigilance programme of India, thus, greatly improving patient safety. Further studies, especially in the private sector regarding newer interventions in the form of incentives to doctors and ADR drop-boxes can reveal innovative ways to improve ADR reporting from private sector doctors, thus ensuring patient safety.

\section{CONCLUSION}

The current study provided an overall insight into the current status of knowledge, attitude and practice of private practitioners of urban areas of Odisha regarding PVPI. The average knowledge level was found to be quite acceptable though a little knowledge gap was observed. The study suggests that frequent awareness programmes regarding PVPI should be made for the doctors in private sectors. Though underreporting was found out to be common phenomenon, the overall attitude was appreciably good among private doctors. Thus, private practitioners can play a major role in contributing to success story of PVPI provided proper motivation and awareness programmes are implemented targeting private practitioners.

\author{
Funding: Indian Council of Medical Research \\ Conflict of interest: None declared \\ Ethical approval: The study was approved by the \\ Institutional Ethics Committee
}

\section{REFERENCES}

1. Rishi RK, Patel RK, Bhandari A. Under reporting of ADRs by medical practitioners in India - results of pilot study. Adv Pharmacoepidem Drug Safety. 2012;1:112.

2. Ramesh M, Pandit J, Parthasarathi G. Adverse drug reactions in a south Indian hospital-their severity and cost involved. Pharmacoepidemiol Drug Saf. 2003;12(8):687-92.

3. Davis EC, Green CF, Taylor S, Williamson PR, Mottram DR, Pirmohamed M. Adverse drug reactions in hospital in-patients: a prospective analysis of 3695 patient-episodes. PLos ONE. 2009; 4:e4439.

4. Healthcare in India. Wikimedia Foundation, Inc. Available at http://en.wikipedia.org/wiki/ Healthcare_in_India\#Public_and_private_sector.

5. Gupta M. Working paper no. 89 state health systems: Orissa. Indian council for research on international economic relations; 2002. Available at http://www.icrier.org/pdf/WP_89.pdf.

6. The Importance of Pharmacovigilance, WHO, 2002. Available at http://apps.who.int/medicinedocs/ pdf/s4893e/s4893e.pdf.

7. Pimpalkhute SA, Jaiswal KM, Sontakke SD, Bajait CS, Gaikwad A. Evaluation of awareness about pharmacovigilance and adverse drug reaction monitoring in resident doctors of a tertiary care teaching hospital. Indian J Med Sci. 2012;66(3-4):5561.

8. Subish P, Izham M, Mishra P. Evaluation of the knowledge, attitude and practices on adverse drug reactions and pharmacovigilance among healthcare professionals in a Nepalese hospital: a preliminary study. The Internet Journal of Pharmacology. 2007;6(1).

9. Lopez-Gonzalez E, Herdeiro MT, Figueiras A. Determinants of under-reporting of adverse drug reactions: a systematic review. Drug Saf. 2009;32:19-31.

10. Smith CC, Bennet PM, Pearce HM, Harrison PI, Reynolds DJ, Aronson JK, et al. Adverse drug reaction in a hospital general medical Unit meriting notification to the committee on safety of medicines. Br J Clin Pharmacol. 1996;42:423-42.

11. Feely J, Moriarty S, O'Connor P. Stimulating reporting of adverse drug reaction by using a fee. $\mathrm{Br}$ Med J. 1990;300:22-3.

12. Inman WH. Attitudes to adverse drug reaction reporting. Br J Clin Pharmacol. 1996;41:433-5. 
13. Gupta P, Udupa A. Adverse drug reaction reporting and pharmacovigilance: knowledge, attitudes and perceptions amongst resident doctors. J Pharm Sci Res. 2011;3:1064-9.

14. Kharkar M, Bowalekar S. Knowledge, attitude and perception/practices (KAP) of medical practitioners in India towards adverse drug reaction (ADR) reporting. 2012;3(3):90-4.

15. Agarwal R, Daher AM, Ismail NM. Knowledge, practices and attitudes towards adverse drug reaction reporting by private practitioners from Klang valley in Malaysia. Malays J Med Sci. 2013;20(2):52-61.

16. Belton KL, Lewis SC, Payne S, Rawlins MD, Wood SM. Attitudinal survey of adverse drug reaction reporting by medical practitioners in the United Kingdom. Br J Clin Pharmacol. 1995;39(3):223-6.

17. Desai CK, Iyer G, Dikshit RK. An evaluation of knowledge, attitude, and practice of adverse drug reaction reporting among prescribers at a tertiary care hospital. Perspect Clin Res. 2011;2(4):129-39.

18. Praveen S, Prakash JR, Manjunath GN, Gautham MS, Kumar N. Adverse drug reaction reporting among medical and dental practitioners: a KAP study. IJMS. 2013;4(1):10-5.

19. Dang A, Rataboli PV. Adverse drug reaction (ADR) notification drop box: an easy way to report ADRs. Br J Clin Pharmacol. 2008;66(5):723-4.

Cite this article as: Swain TR, Nityadarshini N, Pattnaik S, Swain KP. Knowledge, attitude and practice (KAP) study regarding pharmacovigilance programme of India among private practitioners in urban Odisha, India. Int J Basic Clin Pharmacol 2016;5:1315-20 